\title{
The Present Situation and Countermeasures of Building Electrical Equipment Installation and Debugging
}

\author{
Liu Guanghui \\ Guangdong Construction Polytechnic Guangdong, Guangzhou, 510440
}

Keywords: Construction; Electrical equipment; Installation and debugging

\begin{abstract}
In the process of building electrical equipment installation, if there is a certain problem, it not only affects the construction quality of power supply, but also affects the construction safety. This paper puts forward corresponding countermeasures aiming at building electrical equipment installation and debugging.

Construction electrical equipment installation and debugging quality directly affects the whole construction's power supply quality and safety and makes corresponding security which can maximally guarantee personal safety and reduce economic loss. But, at present our country's construction electrical equipment installation and debugging still have many problems that cannot be ignored, which cause a certain degree of negative impact on the quality of power supply in China. At the same time, it also causes certain negative influence on people's daily life. Therefore, based on the problems existing in current building electrical equipment installation and debugging in our country, this paper analyzes effective measures to deal with these problems and provide some reference and guidance for our country's power grid health, sustainable power supply (protect the quality and safety of power supply).
\end{abstract}

\section{BUILDING ELECTRICAL EQUIPMENT INSTALLATION AND DEBUGGING}

\section{A. Size does not match}

In the process of building electrical equipment installation and debugging, we often find that the basic sizes mismatch phenomenon of steel plate, transformer and gauge, ark is serious. At present the most significant part of our country's construction electrical equipment installation and debugging is: transformer plate and tank installation and debugging. They are generally not installed directly on the ground, and often installed on dry base steel, however, dry base steel bridge often has to be solid welded with grounding line, and then connects to the transformer plate and tank and is unified fixed on the civil base steel seat. Therefore, in the whole building electrical equipment installation and debugging, if basic sizes of steel plate and transformer and ark do not match, electrical equipment cannot effectively and accurately be in place, which inevitably will cause basic safety accidents and need basic reconstruction [1].

B. Layout is not reasonable

In the process of building electrical equipment installation and debugging, the cable line layout is unreasonable, which often seriously affects cable construction process and quality. At present, the construction cable line pipe generally uses clay pipe, concrete pipe and plastic pipe, and tends to have too small size of cable line pipe hole at the bottom of the well. Set cable hole well in the corner and branches and in a straight line, also set a certain number of cable into the hole well. But, in the whole cable line pipe laying cable process, construction personnel often make restricted movement, resulting in a certain distance interval. All these need to set the cable into cable hole well, and then develop forward laying work. This thus increases the time, effort and even money loss [2]. In addition, we often find that a construction unit built hole bottom hole size is small, and it is difficult to effectively accommodate construction personnel for electrical equipment installation and debugging. Such unreasonable layout often affects the entire electrical equipment installation and debugging process, and at the same time it also causes a certain degree damage to the membrane of the hole well, influencing people's normal life. 


\section{Seal is not tight}

In the process of building electrical equipment installation and debugging, we often find that the plugging of channel exit as well as the corresponding cable pipe hole is poor. Closely plug export channel and the corresponding cable hole is to effectively prevent the spread of electrical fire, prevent small animals entering and prevent external water infiltration [3]. However, at present our country's construction electrical equipment installation and debugging are often neglected by people because channel exit as well as the corresponding cable tube holes is under the ground. Especially in the maintenance and installation of cable laying cable, the original plugging need removal and because of the neglect, blocking omissions are often caused, resulting in different forms, different levels of security incidents, and at the same time, the seal is not tight. To a large extent, it will cause casualties, and is not conducive to social harmony.

D. Transport channel is not smooth

For high-rise buildings, perfect transformer room installation and debugging building ensures smooth current transport channel and safeguard the normal operations of the high-rise buildings. However, at present, our country's high-rise buildings distribution is often set on the floors or within the basement, and the position is more remote, which is likely to cause a series of current transport channel problems, also it is not conducive to timely confirm the essence of the problems. So it is difficult to smoothly carry out relevant work, at the same time, it causes adverse impact on people's normal life, work, etc.

\section{BUILDING ELECTRICAL EQUIPMENT INSTALLATION AND DEBUGGING TREATMENT COUNTERMEASURES}

\section{A. Hold good size}

Throughout the building construction, especially before electrical equipment installation and debugging, professional electrical personnel should make scientific design, audit base steel plate, transformer and track, tank size, and make sure that they match protection and construction. In the whole process of installation and debugging, according to the actual situation of the construction, timely adjust design, construction scheme, and maintain close cooperation and mutual supervision and inspection with construction personnel from the beginning to the end. In addition, make clear and detailed design for the entire electrical equipment installation construction requirements, and in actual operation, once appear abnormal incidents, contact the relevant department and in a timely manner notify the construction personnel for scientific and reasonable adjustment in the form of text, thus effectively guarantee that base steel plate, transformer plate and gauge and tank size match the basic sizes and improve the quality and safety of electrical equipment installation and debugging [4].

\section{B. Scientific and reasonable layout}

Before setting cable pipe, fully consider construction personnel accommodate situation. On the basis of meeting the requirements of bending radius of the cable, design all corners and right angles around the wall in the hole well as camber angle, and install electrical equipment adjustment. In cable tube radiation, in advance bury the hanging pulley anchor on lift ring well, and take control of certain angle in burying area to ensure the safety of cable pipe lying. In addition, at the top of the hole well, prevent beforehand middle head brackets among cables. The purpose of doing that is for convenient construction, and facilitating the installation, maintenance and repair of cable middle head, thus ascend the overall electrical equipment installation and debugging efficiency and quality and reduce hidden security dangers.

\section{Tight seal}

Whether before or after electrical equipment installation and debugging, ensure that the channel exit as well as the corresponding cable pipe hole are tightly sealed, and in the civil, choose waterproof equipment. When the cable is through the wall, floor, shaft, electric plate, make a tight seal with fireproof materials, and ensure that there is no obvious crack or visible gap in the seal. For bigger hole channel exports and the corresponding cable pipe holes, check real-time containment 
and timely block again to avoid safety problems so as to effectively promote the ascension of quality and safety of building electrical equipment installation and debugging [5]. Specific measures include: (1) before the wire is getting through the tube, do tube processing. The main purpose is to clear tube residual sewage and sundry. The general approach is to tie broken cloth on steel wire and pull back and forth several times to clean the tube. For longer line or more bend steel pipes' a few wire and tube wall friction, blow in talcum powder for convenient threading. (2) This is to check the pipeline flow, and check the location of the boxes and see whether it can meet the construction requirements. For more bend and longer pipe, make the lead in pipe laying, and when jigsaw is blocked, stir at the same time two iron wires to make the ends hook together and pull out the wire. (3) It is forbidden to have a twist wire tube junction and connector, and wire connector is forbidden to connect directly to the box bottom wall, such as joints must be set up within the box, and should set reserved length in the box. Reserve $150 \mathrm{~mm}$ for the wire length in the lamp box, socket, switch, terminal box, and the reserved conductor length in power distribution should be set to half of its circumference, and wire outside reserve the length of $1.5 \mathrm{~m}$ as required [6]. (4) Pay attention to color split phase of the conductor through the tube. L1, L2, L3, are respectively yellow, green, and red. Neutral line and PE line are generally light blue and green/yellow double color. When threading, generally require to appropriate adjust each line to balance the load.

\section{Transport channel is smooth}

In the whole building electrical equipment installation and debugging, consider if the electrical design is in accordance with the relevant requirements. What is more important is to consider whether the current transport channel is unobstructed. Set up current transport special inspection and repair team, and periodically review its smooth degree. Once find any impeded, timely dredge and improve the comprehensive quality of related personnel and strengthen their safety consciousness to reduce the hidden security danger [7]. In addition, according to the actual situation of our country, it is necessary to continuously optimize high-rise building arrangement distribution in order to guarantee smooth transport. Do socket set way wire line $\phi>32 \mathrm{~mm}$, connect screw $\geqslant$ 2 , and ensure the electrical and mechanical strength. When JDG conduit is longer or there are curved lines, to avoid too large threading resistance or line bend break, satisfy the following construction standards: without bending pipe length $\leqslant 30 \mathrm{~m}$; There is a curved pipe length $\leqslant 15$ $\mathrm{m}$; Three bents pipe length is $\leqslant 8 \mathrm{~m}$. If the length is more than the standard, choose a larger diameter or add connection box, and select special grounding connection for cable and pipe connection.

\section{E. Distribution box, cabinet installation and grounding}

Distribution box and cabinet installation are after civil construction completion and as well as State boxing on the wall column. Installation box set is generally before construction plaster decoration, and installed according to the thickness of plaster of the construction site. Ensure that components in the construction are complete with accurate appropriate box body opening position. There is no cross in trunk lines, and the arrangement is in order with loop number clarity and the wiring is tied neatly [8]. Grounding technological process is: grounding body lines $\rightarrow$ down-lead dark set $\rightarrow$ lightning protection equalizing ring $\rightarrow$ set lightning protection network $\rightarrow$ test the resistance $\rightarrow$ natural foundation grounding. According to the design specification, equipment must not be charged during normal use, but in accidents, all possible charged metal case must be grounding specification or zero, such as transformer switch and metal base, the shell and neutral point operation, cable protection tube, cable head metal outsourcing, grounding resistance $\leqslant 1 \Omega$. Grounding is completed under the guidance of professionals, and in structure main steel welding wire jumper binding, building doors and windows has no need of grounding and set in advance good grounding terminal. If grounding wire uses copper wire, casing and grounding body are necessary to connect. After the completion, do resistance test. 


\section{CONCLUSION}

To sum up, with the rapid development of China's socialist market economy, people's living standards are in continuous improvement. Both in industrial production and People's Daily life are more and more in demand of electricity, building electrical equipment installation debugging problems cannot be ignored, which directly affect people's production, living. According to the actual situation of our country, combine the actual requirement of the construction and solve the targeted problems. As far as possible maintain right size, scientific and rational layout, tight sealing security and smooth transport to improve electrical equipment installation quality and safety. In order to effectively guarantee the construction power supply quality and safety, timely avoid the possible problems in electrical equipment installation and debugging. Based on years of practical experience, this article argues the problems and treatment methods in building electrical equipment installation debugging.

\section{REFERENCES}

[1] Chen Jinliang. Introduction to electrical equipment installation and commissioning quality control [J]. China's New Technology New Products, 2012 (8) : 74-74.

[2] Li Yong. Practical study of electrical equipment installation and debugging [J]. Science and Technology Wealth Guide, 2010 (16) : 139155.

[3] Lin Xiuguang. Electrical equipment installation and debugging in construction engineering[J]. Journal of Electronic Commerce in China, 2012, (11) : 215-215.

[4] Zeng Fanli, Liang Xueming. Quality control measures of electrical equipment installation [J]. Journal of Farmer Science and Technology, 2015, (1) : 176-176.

[5] Dong Yujun. Building electrical equipment installation and debugging [J]. Urban Construction Theory Research (Electronic Version), 2012, (21).

[6] Li Haibin. The prevention and control measures of electrical equipment installation and commissioning quality control measures [J]. Urban Construction Theory Research (Electronic Version), 2013, (11).

[7] Si Kui, Xiong Changwei. Quality control measures for electrical equipment installation and debugging [J]. Journal of Youth, 2015, (16) : 381-381.

[8] Wan Sheng. Electrical equipment installation and debugging management operation method research [J]. Construction of Shanxi Province, 2015, (31) : 250-251. 